\title{
Correlation of Parameters used to Estimate Monomer Conversion in a Light-cured Composite
}

\author{
F.A. RUEGGEBERG and R.G. CRAIG ${ }^{1}$
}

Department of Dental Materials, School of Dentistry, Medical College of Geongia, Augusta, Georgia 30912; and 'Department of Biologic and Materials Sciences, School of Dentistry, University of Michigan, Ann Arbor, Michigan 48109

\begin{abstract}
The sensitivities of Fourier transform infrared spectroscopy, Knoop hardness, water sorption, and resin leaching were compared for their ability to distinguish differences between composite samples cured through different thicknesses of overlying resin. The method developed allowed samples of light-cured composite to be made with controlled conversion for parameter testing, and eliminated effects of resin lost to slurry during polishing or an increase in conversion as a result of heat generated during grinding. Sensitivity to differences was greatest and equal for FTIR spectroscopy and Knoop hardness, while resin leaching proved to have moderate sensitivity, and water sorption none. The ability of these parameters to predict monomer conversion as measured by FTIR spectroscopy was also determined. Knoop hardness proved the best conversion predictor, resin leaching the next best, and water sorption the worst. Water sorption values did not vary with changes in specimen conversion.
\end{abstract}

J Dent Res 67(6):932-937, June, 1988

\section{Introduction.}

The degree of monomer conversion in composite resins has been shown to affect greatly the physical properties of this restorative material (Vankerckhoven et al., 1982; Ferracane, 1985). The degree of conversion in light-cured composites varies within the bulk of the specimen because the conversion process is dependent upon light energy for activation (Cook, 1983; Ruyter and Øysaed, 1982). Resin formulation among manufacturers also varies and will affect extent of conversion (Asmussen, 1982b; Ruyter and Svenson, 1978; Vankerckhoven et al., 1981). As a result, the physical properties of light-cured composites will vary with formulation and with depth from the irradiated surface. There are no American Dental Association specifications for light-cured composites with respect to depth and extent of conversion. Analysis of the degree of conversion is expensive and time-consuming. Hence, many investigators have studied the relationship between degree of conversion and surface hardness (Asmussen, 1982a; Ferracane, 1985), translucency (Leung et al., 1984), thickness of scraped sample (De Baker et al., 1985), and strength (Asmussen, 1982a; Ferracane et al., 1982; Tirtha et al., 1982; Vankerckhoven, 1982) with the hope of finding an easier, indirect method to evaluate the extent of cure. In preparing samples for these tests, specimens are often sawed from cylinders or polished to meet the needs of experimental apparatus (Asmussen, 1982a; Cook, 1980; Dewald and Ferracane, 1987; Eliades et al., 1987; Ferracane, 1985; Matsumoto et al., 1986; Onose et al., 1985; Söderholm, 1984). Changes in resin content of a specimen are possible as a result of the leaching of unreacted monomer into the slurry during polishing. Changes

Received for publication November 27, 1987

Accepted for publication February 24, 1988

Based on the partial fulfillment of the Master of Science Degree, School of Graduate Studies, University of Michigan, Ann Arbor, MI

This investigation was supported by Training Grant DE07057 from the National Institute of Dental Research, National Institutes of Health, Bethesda, MD 20892. in the degree of conversion from heat generated by friction during sawing or polishing are also possible (Vankerckhoven et al., 1982). When evaluating monomer conversion of commercial products, Asmussen (1982b) separated the filler and resin phases prior to polymerization, and hoped that conversion of the unfilled resin would mirror that of the filled. Depending upon methodology, samples tested for degree of conversion by Fourier transform infrared (FTIR) spectroscopy may not be suitable for further parameter evaluation, because the sample may be destroyed during removal from the testing device (Ruyter and Øysaed, 1982).

The purposes of this study on a light-cured composite were to: (1) design a testing procedure in which the degree of conversion could be controlled and measured in a filled composite while not subjecting the specimen to grinding or polishing in order to eliminate variables affecting solubility and conversion and to preserve the specimen for further parameter testing; (2) determine and compare the sensitivities of Knoop hardness, water sorption, resin leaching, and monomer conversion for distinguishing differences in samples made by curing through different thicknesses of overlying composite; and (3) evaluate the ability of Knoop hardness, water sorption, and resin leaching to predict the extent of monomer conversion.

\section{Materials and methods.}

The concept of sample preparation was to simulate the exposure of a $0.5-\mathrm{mm}$-thick section of composite material at different depths within a bulk of composite. Fig. 1 is a schematic sketch of the specimen preparation. The specimens, cured overlays and underlays were made from the same batch of light-cured composite, P-30 (3M Company, St. Paul, MN). The underlays were $2 \mathrm{~mm}$ thick and served as reflective material, while the overlays were used to control the amount of light reaching the specimen, and thus the specimen conversion. Optical oil (Type B, Cargille Labs, Cedar Grove, NJ) was placed between the underlays and overlays and a 2 mil Mylar

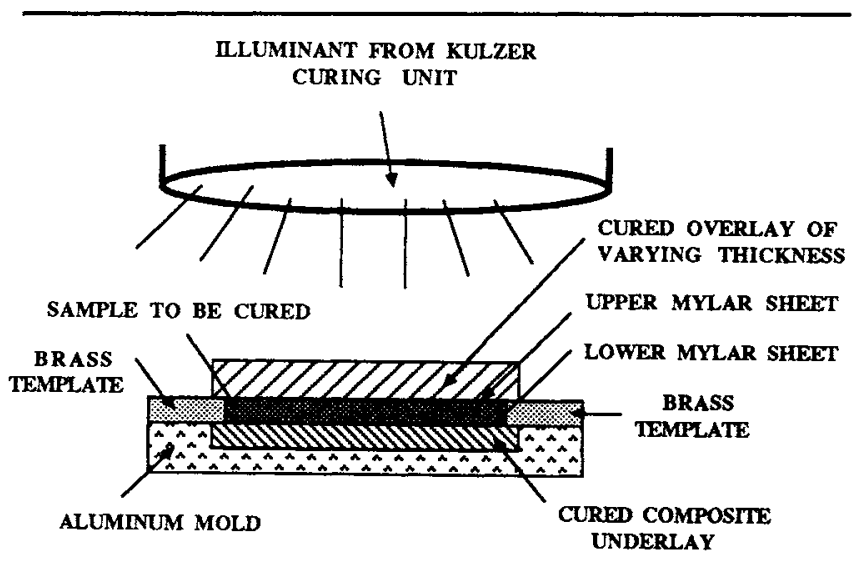

Fig. 1 - Cross-section of specimen preparation. 
(E.I. DuPont Company, Wilmington, DE) sheet in order to enhance transmission of light (Fan et al., 1984). Composite paste was extruded into the mold under an argon atmosphere and low lighting conditions. Overlays of various thicknesses were made by the layering of cured composite thicknesses of $0.5,1.0$, and $2.0 \mathrm{~mm}$ with optical oil, which provided thicknesses in $0.5 \mathrm{~mm}$ increments from 0 to $4.5 \mathrm{~mm}$. Specimens measured $10 \mathrm{~cm}$ wide, $40 \mathrm{~cm}$ long, and $0.5 \mathrm{~mm}$ thick. During specimen curing, the die assembly with appropriate overlays was placed in an indexed position within a Kulzer light-curing unit (Dentacolor XS, Kulzer and Co., Friedrichsdorf, W. Germany) and was exposed for $90 \mathrm{sec}$. Specimens were stored at room temperature in $35-\mathrm{mm}$ film canisters with a desiccant pouch (Sorb-it Packets, N.T. Gates Co., Pennsauken, NJ). Five samples were made for each overlay thickness, resulting in a total of 50 . The order of sample preparation with respect to overlay thickness was randomized (Remmington and Schork, 1985).

The degree of conversion was monitored in a manner similar to that of Vankerckhoven et al. (1982). The aliphatic carbonto-carbon $(\mathrm{C}=\mathrm{C})$ double-bond absorption peak at $1637 \mathrm{~cm}^{-1}$ and aromatic $(\mathrm{C}=\mathrm{C})$ absorption peak at $1608 \mathrm{~cm}^{-1}$ were measured on a FTIR spectrophotometer (60SX, Nicolet Analytical, Madison, WI). Attenuated total reflectance was used with a KRS- 5 crystal. The side of the specimen that had been closest to the light-curing bulb was placed against the crystal face, and pressure was applied to obtain maximum specimen contact. Standard solutions of triethyleneglycol dimethacrylate (Lot 326-31-1, Esschem Company, Essington, PA) and Bis Phenol A (Lot 13-302, Esschem Company, Essington, PA) were prepared in increments of $0.5 \mathrm{~mol} / \mathrm{L}$ from $0.5 \mathrm{~mol} / \mathrm{L}$ to 5.0 $\mathrm{mol} / \mathrm{L}$ in spectrographic-grade ethanol. From these solutions, a calibration curve was generated allowing for correlation of $(\mathrm{C}=\mathrm{C})$ absorption ratios with known molar concentration ratios. Absorption values were determined from baselines which connected the troughs on either side of both the aromatic and aliphatic peaks. Using this baseline method, we obtained a linear relationship ( $\mathrm{r}=0.99$ ) between molar concentration and absorbance ratio. Five replicate absorption ratios for the uncured P-30 paste were determined, and the mean ratio was considered to be the molar ratio value at which $100 \%$ residual $(\mathrm{C}=\mathrm{C})$ remained. Absorption ratios from cured specimens could then be converted into percent remaining $(\mathrm{C}=\mathrm{C})$. Composite samples were tested for conversion at least 24 hours after being made (Ferracane, 1985). Samples were returned to the film canister and stored at room temperature. A one-way analysis of variance with Scheffé intervals at the $95 \%$ level of confidence was performed to detect significant mean group conversion differences as a function of overlay thickness.

Ten hardness readings were recorded on each sample in a longitudinal manner by means of a Tukon hardness tester (Model MO, Wilson Instruments, Bridgeport, CT) and a load of $25 \mathrm{~g}$. The illuminant of the Tukon tester was filtered (Wratten \#25, Eastman Kodak, Rochester, NY) to inhibit further photo-activation of the specimens. A mean value was determined for each sample, and the results were subjected to a one-way analysis of variance, with Scheffé intervals at the 95\% level of confidence used to detect significant mean group hardness differences as a function of overlay thickness.

Values for water sorption were corrected for the amount of resin lost to solution (Rs) in a manner similar to that of Fan et al. (1985). The specimen was weighed (So), placed in a vial containing $10 \mathrm{~mL}$ of distilled water for 28 days, and reweighed $(\mathrm{Sw})$. It was then desiccated to dryness for 28 days and weighed (Sd). Values for the amount of water absorbed by the specimen $(W)$ were determined by the following equations:
Resin leaching to solution

Wet sample weight

Water sorbed by sample, or by substitution

$$
\begin{aligned}
& (\mathrm{Rs})=\mathrm{So}-\mathrm{Sd} \\
& (\mathrm{Sw})=\mathrm{So}+\mathrm{W}-\mathrm{Rs} \\
& (\mathrm{W})=\mathrm{Sw}-\mathrm{So}+\mathrm{Rs} \\
& (\mathrm{W})=\mathrm{Sw}-\mathrm{Sd}
\end{aligned}
$$

The organic content of the batch of composite used was determined gravimetrically by ashing in accordance with ISO Specification \#4049, section 5.7 (ISO, 1978). The mean value of five replications was used as the organic content representative of all specimens made $(\mathrm{Om})$. The water sorption of each specimen was calculated as follows:

$$
\begin{array}{ll}
\text { Resin in pre-wet specimen } & (\mathrm{Ro})=\mathrm{Om}^{*} \text { So } \\
\begin{array}{ll}
\text { Resin in desiccated specimen } \\
\text { Water sorption }
\end{array} & (\mathrm{Rd})=\mathrm{Ro} \text {-Rs } \\
\text { Wr } / \mathrm{Rd}
\end{array}
$$

Water sorption was reported in milligrams water absorbed per gram of organic content of the desiccated specimen. A one-way analysis of variance was performed with Scheffé intervals at the $95 \%$ level of confidence used to observe sorption differences among specimens as a function of overlay thickness.

Resin leaching (RI) was expressed as the quotient of the milligrams of organic content lost to solution (Rs) divided by the grams of organic content in the pre-wet specimen (Ro) per $\mathrm{mL}$ of water. The calculation was made using equation 8:

$$
\text { Resin leaching } \quad(\mathrm{RI})=(\mathrm{Rs} / \mathrm{Ro}) / \mathrm{mL}
$$

A one-way analysis of variance was performed with Scheffé intervals at the $95 \%$ level of confidence used to observe leaching differences among samples as a function of overlay thickness.

In order to validate the use of layered overlays as opposed to solid thicknesses, transmission values at $470 \mathrm{~nm}$ of nonlayered overlays were made on a spectrophotometer (ACTA CIII, Beckman Instruments, Irvine, CA) with integrating sphere. The specific wavelength of $470 \mathrm{~nm}$ was chosen because absorption of the photo-initiator camphoroquinone is maximal in this spectral region. A plot of specimen thickness versus $\log (\mathrm{Io} / \mathrm{I})$ was then made, where Io is the intensity of light striking the overlay surface and I is light intensity after passing through the overlay. Transmission values of layered thicknesses with optical oil for continuity were compared with values obtained from the curve generated when the non-layered overlays were used.

Graphic plots of all possible overlay comparisons were made. With the use of 10 overlays, there was a total of 45 possible comparisons. The proportion of comparisons indicating significant differences for each parameter tested (as determined by the ANOVA), compared with the total number of possible comparisons, was reported as the testing sensitivity for that particular parameter. For example, if a test method showed 15 of the possible overlay comparisons as significantly different, that parameter would have a sensitivity of $15 / 45$ or 0.33 . A perfectly sensitive test would be able to distinguish between all pairs of specimens made under the possible overlay combinations and would have a sensitivity of $45 / 45$ or 1.00 .

Graphic representation of data was made for each test parameter as a function of overlay thickness. Regression analysis was applied to analyze the predictability of each property parameter with respect to monomer conversion. Combinations of parameters were joined, with step-wise multiple regression analysis used to observe any increase in the ability to predict monomer conversion.

\section{Results.}

Conversion results for the mean of the five replications of each overlay thickness used are displayed in Fig. 2. Maximal 


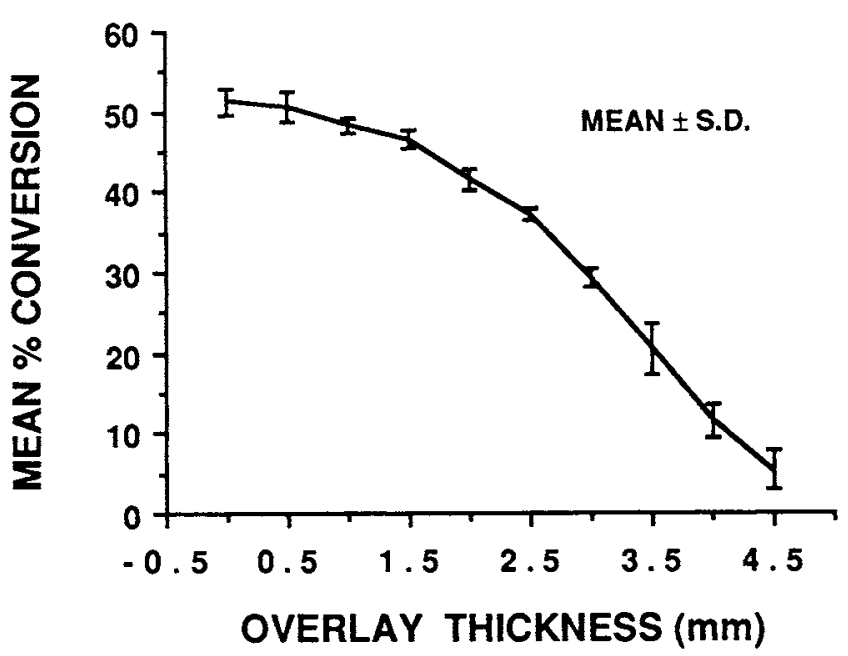

Fig. 2 - Mean sample conversion vs. overlay thickness.

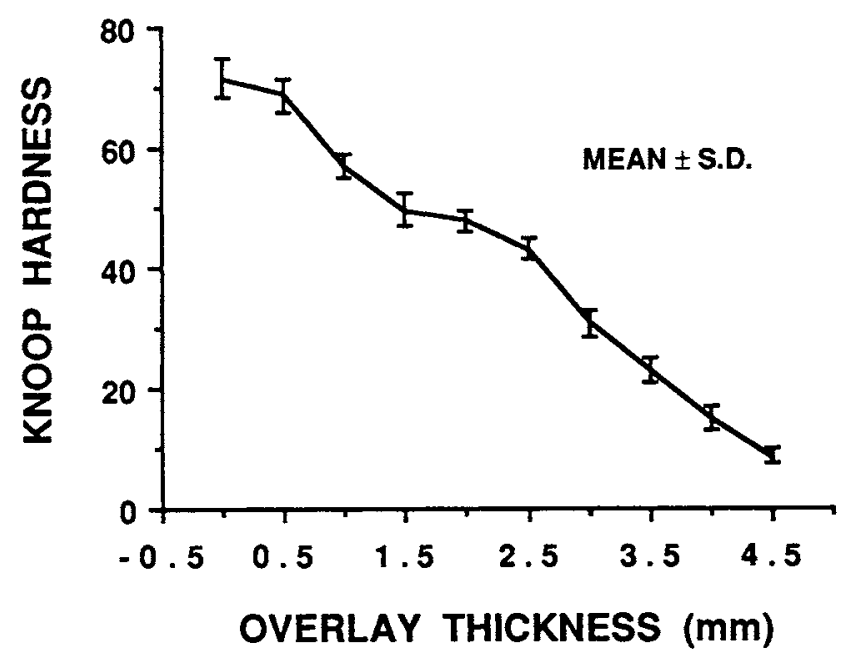

Fig. 3 - Knoop hardness vs. overlay thickness.

conversion of $51 \%$ was noted in specimens with little or no overlay thickness ( 0 to $1.5 \mathrm{~mm}$ ). From 1.5 to 2.5 -mm overlay, there was a decrease in conversion rate with thickness. Conversion values below $2.5-\mathrm{mm}$ overlay declined at an even higher rate, with the lowest conversion $(5 \%)$ noted with the $4.5-\mathrm{mm}$ overlay.

Fig. 3 shows the relationship between mean Knoop hardness and overlay thickness. A similar trend of decrease in parameter value with increase in overlay thickness was noted as observed with degree of conversion. However, there appeared to be a plateau between 1.5 - and $2.5-\mathrm{mm}$ overlay thickness.

The relationship between mean sample water sorption and overlay thickness did not vary as a function of overlay thickness (Fig. 4). Most values of sorption were between 45 and $65 \mathrm{mg} / \mathrm{g}$ regardless of overlay thickness.

Fig. 5 demonstrates the positive correlation between mean sample resin leaching and overlay thickness. As thickness increased, so did resin leaching. The increase in leaching rate showed a marked increase after $2.5 \mathrm{~mm}$ of overlay thickness.

The Table shows the values obtained for light transmission through both layered overlays and calculated values derived from the solid overlay transmission curve. The largest differ-

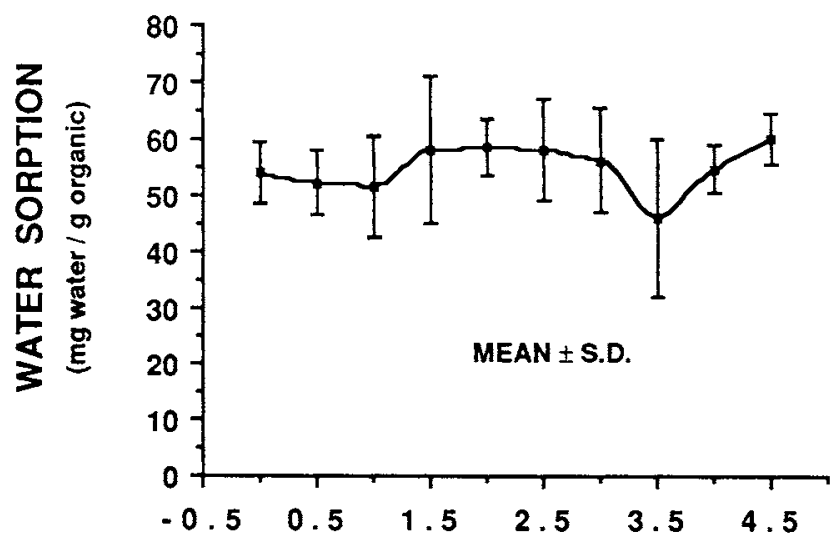

Fig. 4 - Water sorption vs. overlay thickness.

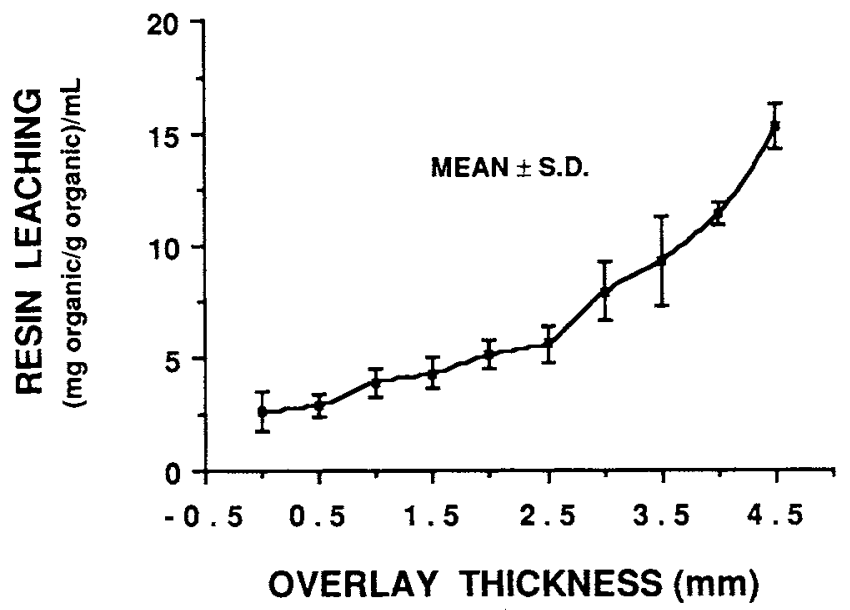

Fig. 5 - Resin leaching vs. overlay thickness.

TABLE

TRANSMISSION DATA OF SOLID AND LAYERED OVERLAYS

\begin{tabular}{cccc}
\hline $\begin{array}{c}\text { Layered } \\
\text { Overlay } \\
\text { Thickness (mm) }\end{array}$ & $\begin{array}{c}\text { Measured } \\
\text { Overlay } \\
\text { Transmission (\%) }\end{array}$ & $\begin{array}{c}\text { Calculated } \\
\text { Overlay } \\
\text { Transmission (\%) }\end{array}$ & $\begin{array}{c}\text { Transmission } \\
\text { Difference (\%) }\end{array}$ \\
\hline 1.44 & 22.2 & 23.6 & 1.4 \\
2.02 & 14.1 & 14.4 & 0.3 \\
2.46 & 10.0 & 9.9 & 0.1 \\
2.60 & 8.5 & 8.8 & 0.3 \\
2.96 & 6.2 & 6.5 & 0.3 \\
3.14 & 5.9 & 5.8 & 0.1 \\
3.40 & 4.5 & 4.5 & 0.0 \\
3.62 & 3.9 & 3.7 & 0.2 \\
3.98 & 2.9 & 2.7 & 0.2 \\
4.14 & 2.5 & 2.4 & 0.1 \\
4.72 & 1.7 & 1.5 & 0.2 \\
\hline
\end{tabular}

ence in percent transmission between the two methods was $1.4 \%$, with the remainder having an average difference of $0.2 \%$.

Parameter sensitivity was designed to test the extent to which a procedure was able to detect differences among specimens made using various thicknesses of overlays. Testing sensitivities are shown in Fig. 6 for all parameters. For example, when one compares degree of conversion in specimens made under overlays of $1.0-$ and $2.0-\mathrm{mm}$ thickness, a significant difference 
OVERLAY THICKNESS (mm)

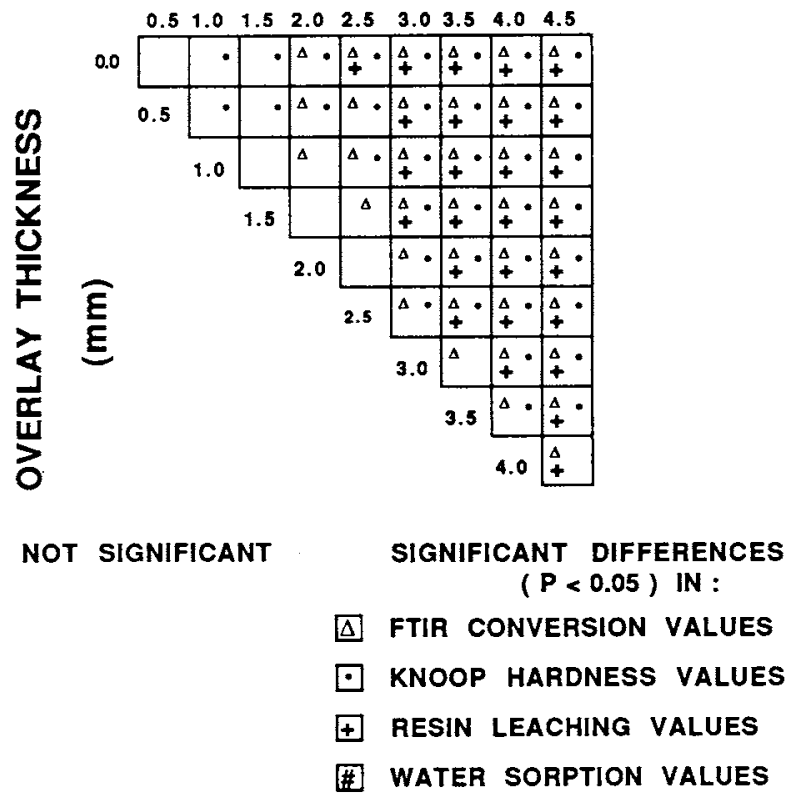

Fig. 6 - Significant differences between parameter and overlay thickness.

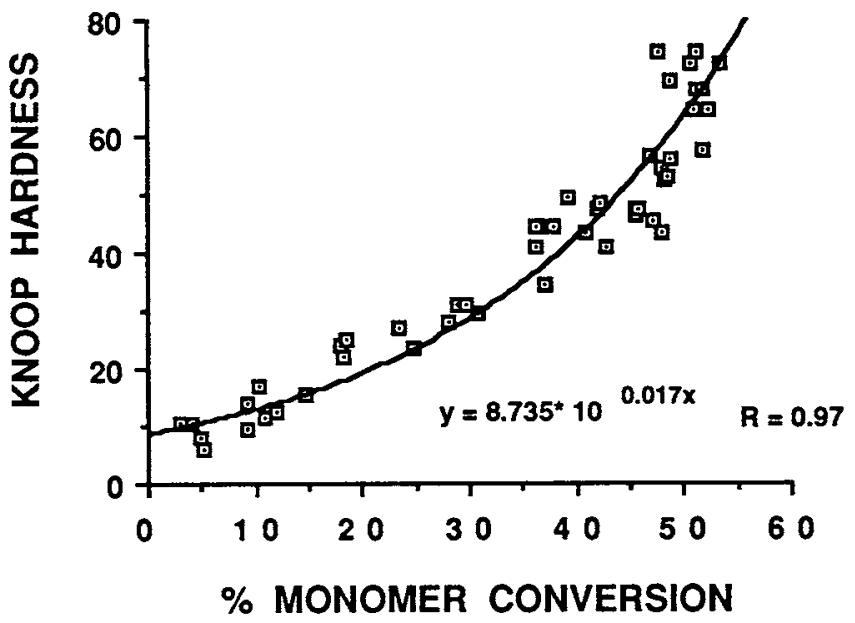

Fig. 7 - Knoop hardness as a function of conversion.

exists. This is noted as a symbol $(\triangle)$ in the appropriate box. However, when we compared Knoop hardness, water sorption, and resin solubility for specimens made under similar conditions, no significant differences were found. Therefore, there is an absence of labels identifying these tests in the appropriate square in Fig. 6. Both degree of conversion and Knoop hardness demonstrated identical sensitivities of 0.82 ; however, the distribution of differences was not similar. Water sorption testing showed a sensitivity of 0.00 . Resin leaching had a sensitivity of 0.60 , with differences appearing at overlay thicknesses of $2.5 \mathrm{~mm}$ and greater.

Fig. 7 shows that the ability of Knoop values to predict percent conversion was high $(r=0.97)$. The relationship increased exponentially, very evident at higher conversion values. Water sorption showed poor predictability of monomer conversion $(r=0.03)$. The relationship was more of a constant than continuous function (Fig. 8). Resin leaching had a strong
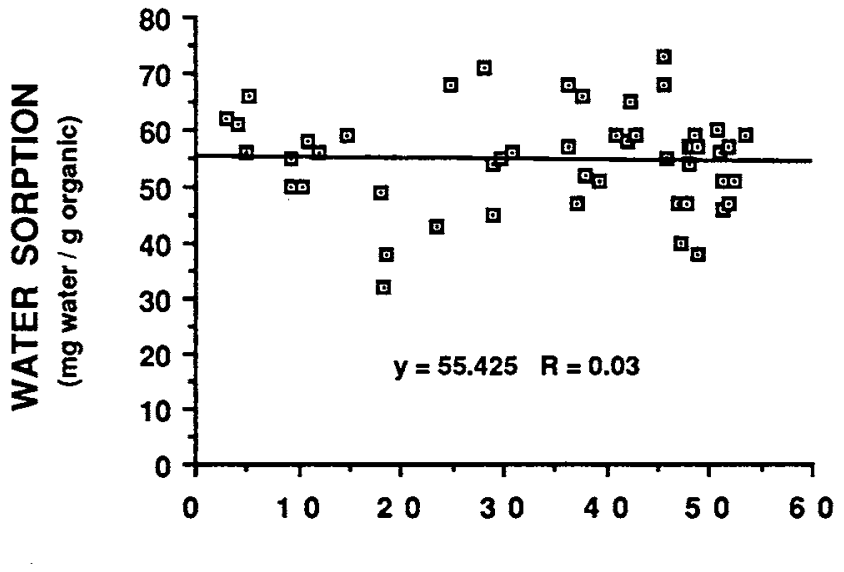

\% MONOMER CONVERSION

Fig. 8 - Water sorption as a function of conversion.

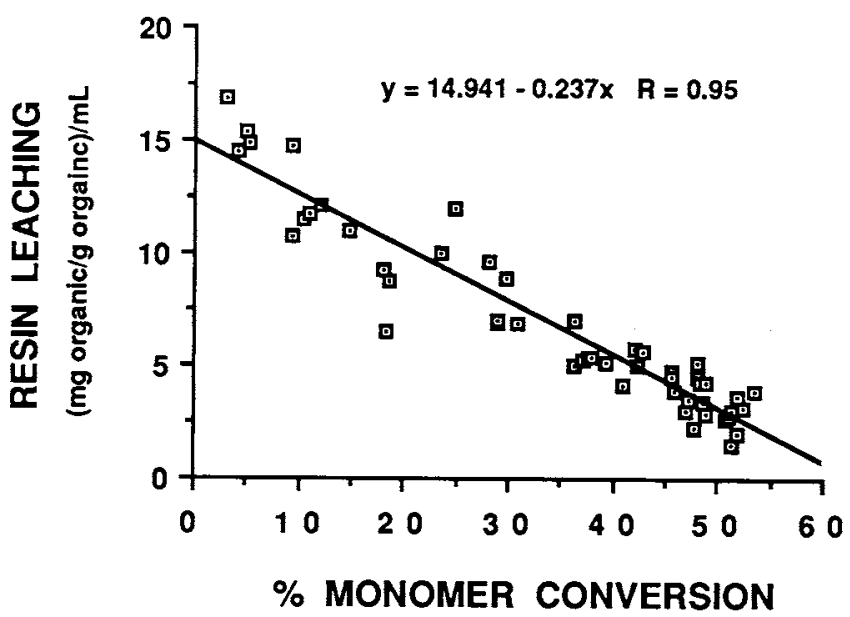

Fig. 9 - Resin leaching as a function of conversion.

$(\mathrm{r}=0.95$ ), inverse relationship to conversion values (Fig. 9). Many of the lower solubility readings were clustered around the high end of conversion readings.

\section{Discussion.}

The goals of obtaining a method to evaluate conversion and auxiliary test parameters in a filled composite system without altering physical properties of the test specimen have been achieved. The validity of stacking overlays to simulate solid samples has been demonstrated. Because cured overlays and underlays have refractive indices and absorbances different from those of the uncured sample, the test specimen may not perfectly mirror a clinical situation. However, the absence of cutting and polishing during specimen preparation was more likely to produce examples of composite representative of that found within the depths of an intact restoration than would a disc from a sawn cylinder. Differences between the rate of decline of hardness and specimen conversion with respect to overlay thickness are not as great when this method is used as compared with other methods using cutting or polishing of specimens (Eliades et al., 1987). The decreased rate of decline in hardness in comparison to conversion seen in other studies may be attributed to increased conversion of the hardness specimen as a result of heat generated during polishing. 
The maximal conversion values of $\mathrm{P}-30$ found in this study were a little more than $50 \%$ and were lower than those found by others (Ruyter and Øysaed, 1987) which ran as high as $60 \%$. The differences in conversion values are attributable to the lower intensity of the laboratory curing light as opposed to an intra-oral unit. Kulzer states that the minimal intensity of light in the spectral region of $320 \mathrm{~nm}-520 \mathrm{~nm}$ is $250 \mathrm{~mW}$ / $\mathrm{cm}^{2}$ for their Dentacolor XS unit. Commercial intra-oral lightcuring units have an intensity of approximately 2 to 3 times the minimal amount claimed for the Kulzer product (Cook, 1982). This decreased intensity of light source would therefore cause a lower maximal curing of the specimens seen in this study as opposed to conversion values reported elsewhere.

Fig. 10 shows the areas where FTIR and Knoop hardness testing differed with respect to discriminating among samples made under various thicknesses of overlays. Hardness was more sensitive at high levels of conversion. This result is in agreement with those of Ferracane (1985), who suggested that hardness is sensitive to small changes in polymer cross-linkages that are found in areas of higher conversion. Conversion testing using FTIR was more sensitive to samples made with thicker overlays. Again, the number of cross-linkages would be fewer in these samples, making hardness testing less discriminating.

In comparison with Knoop testing, resin leaching was only moderately sensitive. It only identified differences after overlays were $2.5 \mathrm{~mm}$ thick or greater.

A surprising result was that water sorption proved insensitive to the thickness of the overlay through which the specimen was cured. Fan et al. (1986) measured water sorption without accommodating for material lost to solution. Their values for water sorption varied with specimen depth. The importance of accounting for the amount of resin leaching into solution when water sorption is calculated is thus emphasized.

It should be stressed that the relationships between test parameters and monomer conversion found in this study are only valid for this brand and batch of composite resin used. Direct extrapolation of relationships to other systems may be invalid because of the effects of filler composition and variation in chemistry.

\section{OVERLAY THICKNESS $(\mathrm{mm})$}
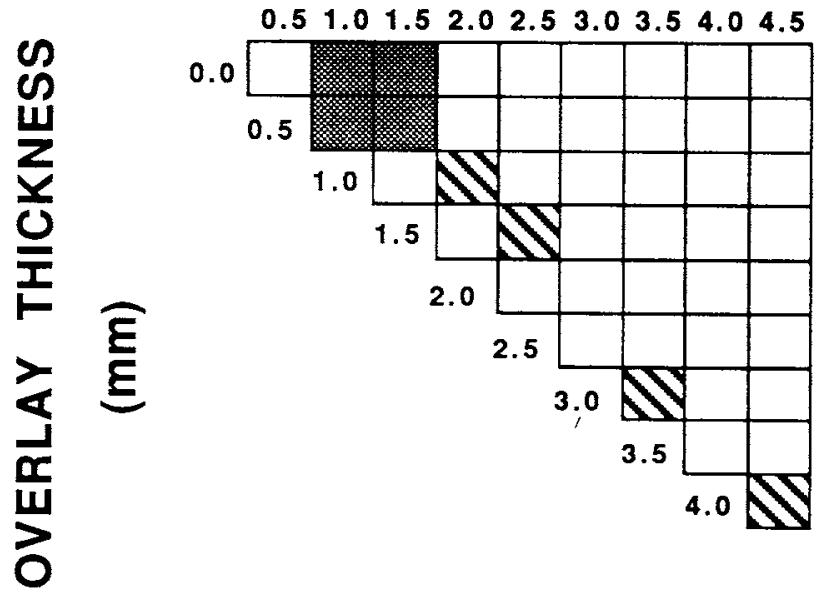

KNOOP SENSITIVITY > FTIR SENSITIVITY

D FIR SENSITIVITY > KNOOP SENSITIVITY

Fig. 10 - Areas where Knoop and FTIR testing differed.
Of all test methods used singly or in combination, Knoop hardness proved to be the best conversion predictor $(r=0.97)$. At first glance, it appears that the exponential increase in KHN seen at high conversions would make this parameter a weak predictor. However, the opposite is true. Because the slope of the prediction line increases with increasing conversion, a small change in conversion will be related to a large change in hardness. This means that as hardness increases, its ability to distinguish between conversions increases. Thus, if a sample conversion were driven higher, there would be a very steep rise in hardness values, making this parameter a very sensitive predictor of conversion, provided that the variation about the prediction line is small.

Resin leaching proved to be the second best predictor of monomer conversion ( $\mathrm{r}=0.95$ ). Extrapolation of leaching values to higher conversions indicates that this parameter would reach a plateau at conversion levels of approximately $60 \%$ and not furnish needed relationships at levels of higher cure. At low values of monomer conversion, the amount of resin entering solution is limited by the solubility of the organic material in water. Over the levels of conversion values examined, the leaching test may be sensitive within a range of cure that would reflect important differences clinically.

Water sorption values were obtained under conditions approaching equilibrium. They showed no significant fluctuation with degree of monomer conversion and as such proved not to be a predictor $(\mathrm{r}=0.03)$. Test results indicated that once the gel had set, the size of interstices inhibiting water diffusion through the polymeric matrix were not significantly different from those when higher conversion values of $50 \%$ were reached.

The adequacy of test sensitivity needs to be addressed when test parameters are compared for cure depth. In the present study, Knoop hardness began to discriminate among samples cured under $1.0-\mathrm{mm}$ overlay, while conversion differences appeared in samples with at least $2.0-\mathrm{mm}$ overlay. Resin leaching proved sensitive only when samples were cured under $2.5 \mathrm{~mm}$ or more.

At the level of $2.5-\mathrm{mm}$ overlay, sample conversion seemed to decline at a higher rate to $72 \%$ of its highest value. At this level, too, Knoop hardness was $60 \%$ of its maximum and quickly declined thereafter. The $2.5-\mathrm{mm}$ level is also where resin leaching began to increase sharply. Perhaps this is the level at which adequate conversion could be said to exist for testing purposes.

The use of resin leaching by gravimetric analysis should be studied as a means for evaluating cure depth. Knoop testing requires extremely flat surfaces as well as special testing equipment. Resin leaching, on the other hand, only requires a means for accurate measurement of mass. When calculated as mg lost to solution divided by the total organic sample content and placed on a per-mL-water basis, the results may be compared among various composite types. Results would not be dependent upon linear measurement of specimen dimensions.

\section{Acknowledgments.}

The authors wish to acknowledge their appreciation for the supply of composite material by the $3 \mathrm{M}$ Company. The talents of Mr. Kim Firestone in preparing custom attachments and the counsel of Dr. Michael Schork in statistical design and interpretation were indispensable.

\section{REFERENCES}

ASMUSSEN, E. (1982a): Restorative Resins: Hardness and Strength vs. Quantity of Remaining Double Bonds, Scand J Dent Res 90:484 489. 
ASMUSSEN, E. (1982b): Factors Affecting the Quantity of Remaining Double Bonds in Restorative Resin Polymers, Scand J Dent Res 90:490-496.

COOK, W.D. (1980): Factors Affecting the Depth of Cure of UVPolymerized Composites, $J$ Dent Res 59:800-808.

COOK, W.D. (1982): Spectral Distributions of Dental Photopolymerization Sources, $J$ Dent Res 61:1436-1438.

COOK, W.D. (1983): Cure of Resin Based Restorative Materials. II. White Light Photopolymerized Resins, Aust Dent $J$ 28:307-311.

DE BAKER, J.; DERMAUT, L.; and BRUYNOOGHE, W. (1985): The Depth of Polymerization of Visible Light-cured Composite Resins, Quint Int 10:693-701.

DEWALD, J.P. and FERRACANE, J.L. (1987): A Comparison of Four Modes of Evaluating Depth of Cure of Light-activated Composites, $J$ Dent Res 66:727-730.

ELIADES, G.C.; VOUGIOUKLAKIS, G.J.; and CAPUTO, A.A. (1987): Degree of Double Bond Conversion in Light-cured Composites, Dent Mater 3:19-25.

FAN, P.L.; EDAHL, A.; LEUNG, R.L.; and STANFORD, J.W. (1985): Alternative Interpretations of Water Sorption Values of Composite Resins, $J$ Dent Res 64:78-80.

FAN, P.L.; KNOEPPEL, R.; KUMAGAI, T.; TOSAKI, S.; LEUNG, R.L.; and STANFORD, J.W. (1986): Composite Resin Depth of Cure Parameters: Hardness, Sorption, Solubility, J Dent Res 65:255, Abst. No. 775.

FAN, P.L.; STANFORD, C.M.; STANFORD, W.B.; LEUNG, R.L.; and STANFORD, J.W. (1984): Effects of Backing Reflectance and Mold Size on Polymerization of Photo-activated Composite Resin, J Dent Res 63:1245-1247.

FERRACANE, J.L. (1985): Correlation Between Hardness and Degree of Conversion During the Setting Reaction of Unfilled Dental Restorative Resins, Dent Mater 1:11-14.

FERRACANE, J.L.; NEWMAN, S.; and GREENER, E.H. (1982): Correlation of Strength and Degree of Polymerization of Unfilled Bis-GMA, IADR Prog \& Abst 61: No. 832.

INTERNATIONAL ORGANIZATION FOR STANDARDIZATION
(1978): Resin-based Dental Filling Materials, International Standard \#4049, Switzerland, ISO.

LEUNG, R.L.; KAHN, R.L.; and FAN, P.L. (1984): Comparison of Depth of Polymerization Evaluation Methods for Photo-activated Composite, J Dent Res 63:292, Abst. No. 1095.

MATSUMOTO, H.; GRES, J.E.; MARKER, V.A.; OKABE, T.; FERRACANE, J.L.; and HARVEY, G.A. (1986): Depth of Cure of Visible Light-cured Resin: Clinical Simulation, $J$ Prosthet Dent 55:574-578.

ONOSE, H.; SANO, H.; KANTO, H.; ANDO, S.; and HASUIKE, T. (1985): Selected Curing Characteristics of Light-activated Composite Resins, Dent Mater 1:48-54.

REMMINGTON, R.D. and SCHORK, M.A. (1985): Statistics with Applications to the Biological and Health Sciences, 2nd ed., Englewood Cliffs, NJ: Prentice-Hall.

RUYTER, I.E. and $\varnothing Y S A E D, H .(1982)$ : Conversion in Different Depths of Ultraviolet and Visible Light Activated Composite Materials, Acta Odontol Scand 40:179-192.

RUYTER, I.E. and ØYSAED, H. (1987): Composites for Use in Posterior Teeth: Composition and Conversion, $J$ Biomed Mater Res 21:11-23.

RUYTER, I.E. and SVENSON, S.A. (1978): Remaining Methacrylate Groups in Composite Restorative Materials, Acta Odontol Scand $36: 75-82$.

SÖDERHOLM, K.-J. (1984): Water Sorption in Bis(GMA)/TEGDMA Resin, J Biomed Mater Res 18:271-279.

TIRTHA, R.; FAN, P.L.; DENNISON, J.B.; and POWERS, J.M. (1982): In vitro Depth of Cure of Photo-activated Composites, $J$ Dent Res 61:1184-1187.

VANKERCKHOVEN, H.; LAMBRECHTS, P.; VAN BEYLEN, M.; DAVIDSON, C.L.; and VANHERLE, G. (1982): Unreacted Methacrylate Groups on the Surfaces of Composite Resins, $J$ Dent Res 61:791-795.

VANKERCKHOVEN, H.; LAMBRECHTS, P.; VAN BEYLEN, M.; and VANHERLE, G. (1981): Characterization of Composite Resins by NMR and TEM, $J$ Dent Res 60:1957-1965. 